\title{
Comparative single-dose pharmacokinetics of sildenafil after oral and rectal administration in healthy beagle dogs
}

\author{
Hyuck-Joo Yang ${ }^{1 \dagger}$, Ye-In $\mathrm{Oh}^{2 \dagger}$, Jong-Woo Jeong ${ }^{3}$, Kun-Ho Song ${ }^{1}$, Tae-Sung Koo ${ }^{3^{*}}$ and Kyoung-Won Seo ${ }^{1 *}$ (D)
}

\begin{abstract}
Background: Sildenafil citrate, a highly selective phosphodiesterase type 5 inhibitor, is used to treat pulmonary hypertension $(\mathrm{PH})$ in veterinary medicine. The objective of this study was to investigate pharmacokinetic profiles by oral administration of orally disintegrating film (ODF) and film coated tablet (FCT) formulations and rectal administration of ODF formulation in healthy dogs. Twelve healthy beagle dogs were administered four separate doses of sildenafil: FCT formulation $2 \mathrm{mg} / \mathrm{kg}$ orally, ODF formulation $2 \mathrm{mg} / \mathrm{kg}$ orally, ODF formulation $2 \mathrm{mg} / \mathrm{kg}$ rectally, and ODF formulation $10 \mathrm{mg} / \mathrm{kg}$ rectally. For 24 hours following administration, blood samples were collected and the plasma concentrations of sildenafil were assayed by liquid chromatography-tandem mass spectrometry.

Results: There were no significant differences in all the pharmacokinetic parameters between FCT and ODF formulations when administrated orally. $C_{\max }$ at the time of rectal administration was lower when the same dose was given as that orally administered. No serious systemic adverse events (AEs) were observed.

Conclusions: These findings suggest that sildenafil ODF formulation can be used as an alternative to FCT formulation in the treatment of canine PH patients; additionally, rectal administration of sildenafil ODF may be a beneficial treatment option for canine patients who are unable to receive medication orally.
\end{abstract}

Keywords: Dog, Orally disintegrating film formulation, Rectal administration, Sildenafil, Pulmonary hypertension

\section{Background}

$\mathrm{PH}$ is a complex syndrome characterized by a persistent, abnormal increase in pulmonary pressure resulting in life-threatening respiratory distress [1]. $\mathrm{PH}$ in dogs can be primary or secondary to other diseases, including heart and pulmonary disease $[1,2]$. The most commonly reported presenting complaints in canine $\mathrm{PH}$ patients are exercise intolerance $(45 \%)$, cough $(30 \%)$, respiratory difficulty (28\%), and syncope (23\%) [3]. In veterinary medicine, sildenafil can decrease pulmonary arterial pressure and improve quality of life of canine patients with $\mathrm{PH}$ [4-7]. In particular, patients with $\mathrm{PH}$ who have respiratory distress are required to receive sildenafil.

\footnotetext{
*Correspondence: kootae@cnu.ac.kr; kwseo@cnu.ac.kr

${ }^{\dagger}$ Hyuck-Joo Yang and Ye-In Oh contributed equally to this work.

${ }^{3}$ Graduate School of New Drug Discovery and Development, Chungnam

National University, Daejeon 34134, Republic of Korea

'Department of Veterinary Internal Medicine, College of Veterinary Medicine,

Chungnam National University, Daejeon 34134, Republic of Korea

Full list of author information is available at the end of the article
}

Sildenafil citrate $\left(\right.$ Viagra $\left.^{\circ}\right)$ is a highly selective phosphodiesterase type 5 inhibitor that enhances nitric oxide mediated pulmonary vasodilatation [8]. Sildenafil is currently used only in oral formulations in veterinary medicine. However, attempting to administer oral medication to canine patients who are in respiratory distress or are receiving oxygen treatment may further exacerbate respiratory conditions or induce aspiration pneumonia. Thus, it is important to consider other forms of medication administration that do not interfere with respiration, such as rectal administration. No animal studies for these alternatives have been conducted so far.

In human medicine, there are two formulations of sildenafil: FCT and ODF. FCT should be administered with water, but ODF is easy to take without water due its effective solubility in the mouth. Owing to the presence of a larger surface area of this formulation and a highly vascularized oral or buccal mucosa, ODF provides rapid disintegration and dissolution in the oral cavity; a previous study show that the pharmacokinetics between FCT 
and ODF formulation do not differ significantly in healthy humans [9]. Due to these advantages, this formulation of drug could be much more suitable for an emergency patient with respiratory distress. Unfortunately, there are no studies that evaluate the pharmacokinetics of ODF formulation of sildenafil in veterinary medicine.

The first objective of this study was to compare the pharmacokinetic profiles of ODF formulation with those of a FCT formulation in healthy dogs when administered orally. The second objective was to investigate pharmacokinetic profiles to determine a dosage for rectal administration of ODF formulation of sildenafil that produced similar therapeutic effects to oral administration.

\section{Results}

The mean plasma drug concentrations of each formulation, route, and dosage are depicted in the Fig. 1. Comparisons of pharmacokinetic parameters between the four arms of treatment are presented in Table 1 and Fig. 2. There were no significant differences in pharmacokinetic parameters between the FCT and ODF formulations when administrated orally. There were increases in $C_{\max }$ and $\mathrm{AUC}_{\text {last }}$ between the rectal $2 \mathrm{mg} / \mathrm{kg}$ and $10 \mathrm{mg} / \mathrm{kg}$ administrations but the increases in values were not dose-proportional. Significant differences in $\mathrm{C}_{\max }$ and $\mathrm{AUC}_{\text {last }}$ were observed between oral administrations and $2 \mathrm{mg} / \mathrm{kg}$ rectal administration. $\mathrm{AUC}_{\text {last }}$ was significantly greater after $10 \mathrm{mg} / \mathrm{kg}$ rectal administrations when compared to $2 \mathrm{mg} / \mathrm{kg}$ oral administrations.
No significant differences were noted in the $T_{1 / 2}$ and $\mathrm{T}_{\max }$ among the four arms.

No serious AEs, such as fatal or life-threatening AEs, or those requiring professional intervention, were observed during the study period. In three dogs, mild vomiting occurred 2 to $3 \mathrm{~h}$ after dosing (two in FCT $2 \mathrm{mg} / \mathrm{kg}$ and one in $2 \mathrm{mg} / \mathrm{kg}$ rectally). Soft stools were observed in five dogs (one in ODF $2 \mathrm{mg} / \mathrm{kg}$, two in $2 \mathrm{mg} / \mathrm{kg}$ rectally, and two in $10 \mathrm{mg} / \mathrm{kg}$ rectally). In the subjects who received sildenafil $10 \mathrm{mg} / \mathrm{kg}$ rectally, soft stools occurred within 15 to $80 \mathrm{~min}$ after administration. Soft stools occurred in at least $2 \mathrm{~h}$ after administration in the other three dogs.

\section{Discussion}

To our knowledge, this study is the first to evaluate the pharmacokinetic profiles of oral and rectal administration of sildenafil ODF formulation in dogs. This study demonstrates that the pharmacokinetic profiles after oral administration of the ODF formulation are very similar those of the FCT formulation in healthy dogs.

In canine patients with respiratory failure due to $\mathrm{PH}$, sildenafil selectively acts on the pulmonary vascular smooth muscle, which reduces the risk of lowering systemic blood pressure $[10,11]$. Therefore, it should be relatively safe to administer in an emergency. In human patients, ODF is administered in the form of one or two films. However, in this study, the films used in the ODF oral administration were cut into pieces as calculated by the body surface area of each subject. In dogs, the ODF dissolved on the tongue very quickly without water, just

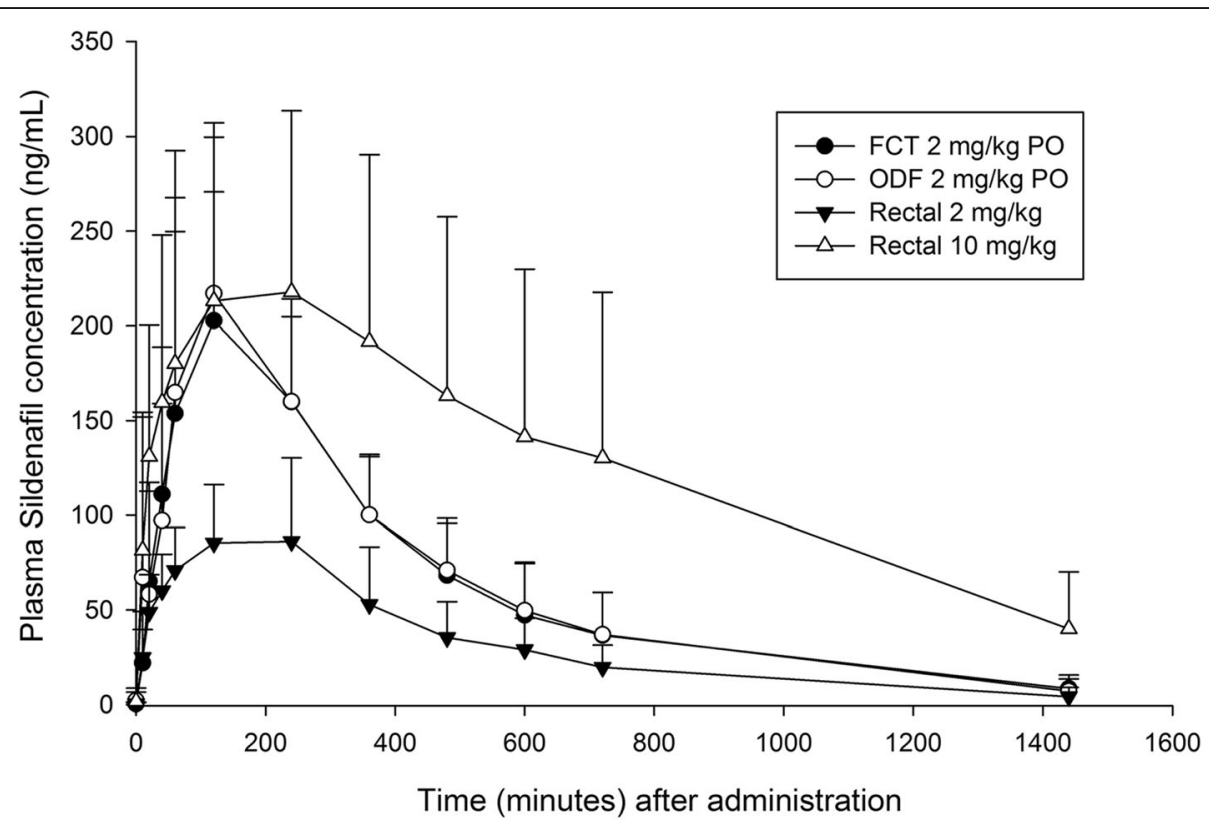

Fig. 1 Mean plasma sildenafil concentrations for each arm. Plasma concentration-time profiles of sildenafil in beagle dogs after single-dose oral and rectal administration. $\mathrm{FCT}=$ Film-coated tablet $\mathrm{PO}$; ODF = Orally disintegrating film PO 
Table 1 Pharmacokinetic parameters of sildenafil in beagle dogs after administration of each arm

\begin{tabular}{|c|c|c|c|c|}
\hline Pharmacokinetic parameters & $\begin{array}{l}\mathrm{FCT}^{\mathrm{a}} \mathrm{PO} \\
2 \mathrm{mg} / \mathrm{kg}\end{array}$ & $\begin{array}{l}\mathrm{ODF}^{\mathrm{b}} \mathrm{PO} \\
2 \mathrm{mg} / \mathrm{kg}\end{array}$ & $\begin{array}{l}\text { Rectal }^{\mathrm{C}} \\
2 \mathrm{mg} / \mathrm{kg}\end{array}$ & $\begin{array}{l}\text { Rectal } \\
10 \text { mg/kg }\end{array}$ \\
\hline$C_{\max }(\mu \mathrm{g} / \mathrm{mL})$ & $0.21 \pm 0.07$ & $0.25 \pm 0.10$ & $0.09 \pm 0.04$ & $0.26 \pm 0.08$ \\
\hline$T_{\max }$ (hours) & $2.08 \pm 1.30$ & $1.88 \pm 1.65$ & $3.28 \pm 2.49$ & $4.30 \pm 2.91$ \\
\hline $\mathrm{T}_{1 / 2}$ (hours) & $5.46 \pm 2.39$ & $4.62 \pm 1.49$ & $4.82 \pm 1.91$ & $4.20 \pm 1.40$ \\
\hline $\mathrm{AUC}_{\text {last }}(\mu \mathrm{g} \cdot \mathrm{h} / \mathrm{mL})$ & $1.52 \pm 0.47$ & $1.51 \pm 0.51$ & $0.77 \pm 0.31$ & $3.12 \pm 1.39$ \\
\hline
\end{tabular}

$C_{\max }$ Maximum plasma concentration. $T_{\max }$ Time at the maximum concentration. $T_{1 / 2}$ Elimination half-life. $A U C_{\text {last }}$ Area under the curve from time zero to time of last measurable concentration

${ }^{a}$ FCT, Film-coated tablet, ${ }^{b}$ ODF, orally disintegrating film, ${ }^{c}$ Rectal, ODF rectal administration

as it does in humans. This study incidentally revealed that ODF formulation of sildenafil is suitable for dogs even if it is administered in the form of cut pieces. Due to the ease of administration and accurate dosage, oral administration of sildenafil ODF could be an appropriate alternative for canine patients with $\mathrm{PH}$ who are not able to swallow any medication. This poses as an advantage since it broadens the prescription options available to veterinarians.

We performed rectal administration of sildenafil ODF formulation, which is rapidly absorbed in the mucous membranes [12]. Some studies have reported rectal administration of medication as an alternative route for dogs that are not able to receive medication orally because of seizure [13, 14]. However, previous studies demonstrated that the dosage for rectal administration should be adjusted because $\mathrm{C}_{\max }$ and $\mathrm{AUC}_{\text {last }}$ (an indicator of bioavailability) after rectal dosing is relatively lower than that after oral administration. Previous studies have also shown that when the same dosage is given, the mean $\mathrm{C}_{\max }$ is about 1.5 to 2.5 times higher when administered orally than when administered rectally $[13,15,16]$. This result demonstrates that rectal administration requires a higher dose than oral administration for obtaining similar plasma concentration. Based on previous research results, we performed a pharmacokinetic evaluation using a dose of sildenafil that was five times greater than that used in oral administration considering the possibility
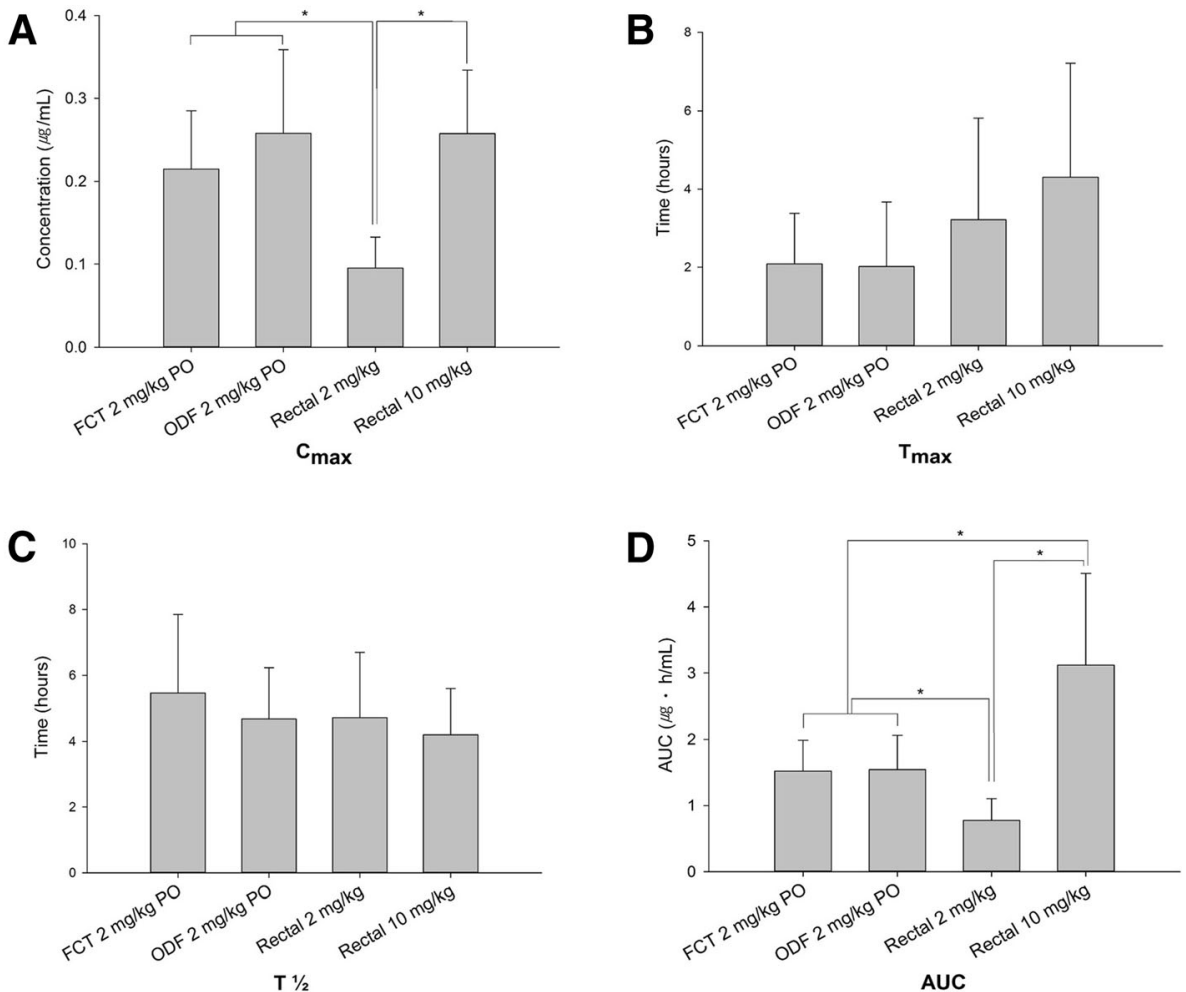

Fig. 2 Comparison of pharmacokinetic parameters between four treatment arms $(\mathbf{a}, \mathbf{b}, \mathbf{c}$ and $\mathbf{d}) . \mathbf{C}_{\max }=$ Maximum plasma concentration. $T_{\max }=$ Time at the maximum concentration. $T_{1 / 2}=$ Elimination half-life. $A \cup C_{\text {last }}=$ Area under the curve from time zero to time of last measurable concentration. $\mathrm{FCT}=$ film-coated tablet PO. ODF $=$ orally disintegrating film PO. *Significantly different $(p<0.05)$ 
that sildenafil may leak out of the rectum. $\mathrm{AUC}_{\text {last }}$ after $10 \mathrm{mg} / \mathrm{kg}$ rectal administration was significantly higher than that after oral administration $(p<0.05)$. This result suggests that the dogs were overdosed with the $10 \mathrm{mg} /$ $\mathrm{kg}$ rectal administration when compared to the $2 \mathrm{mg} /$ $\mathrm{kg}$ PO treatments. Therefore, it is necessary to further investigate the dosage of rectally administered sildenafil that is needed to achieve the same effect produced from oral administration.

Although rectal administration had a tendency to delay the mean $\mathrm{T}_{\max }$ more than oral administration, there were no significant differences in $T_{1 / 2}$ and $T_{\max }$ in the four arms. As a result, regardless of the formulation or administration route of sildenafil, the timing of the clinical effect of the drug can be roughly estimated, which can be helpful for $\mathrm{PH}$ treatment in practice.

According to a previous report, the absorption of a drug decreases in the presence of feces [14]. In an effort to minimize the effects of feces on drug absorption in our study, sildenafil was administered rectally after fasting and administration of enemas. Although we fasted the dogs for $20 \mathrm{~h}$, some dogs defecated after administration of the enema; this is because each dogs' peristaltic movement time may vary [17]. Comparing the standard deviation values of $C_{\max }$ according to the route of administration, it can be concluded that consistent drug absorption occurred after rectal administration. However, it is difficult to perform an enema in canine patients with dyspnea in practice. Furthermore, other factors can affect the pharmacokinetics in rectal administration, including environmental $\mathrm{pH}$, lipophilicity of the drug, and the site of drug deposition in the rectum [18-20]. Further research may be needed to consider these factors on rectal administration of sildenafil in canine patients.

According to the criteria for AEs, serious AEs were not observed [21]. Although six dogs showed mild vomiting (three events) or soft stool (five events), all dogs from the four arms of the study tolerated the experiment well. During the rectal administration, the vomiting and soft stools were suspected to be AEs of sildenafil given that they were observed after the enema for at least $15 \mathrm{~min}$. It is reported that gastrointestinal upset is a possible side effect when sildenafil is administered [22].

This study has some limitations. First, the rectal dosing was administered in only two dosages. The rectal dosing equivalent to the effects $2 \mathrm{mg} / \mathrm{kg}$ of oral dosing was not known. Second, an active metabolite of sildenafil (N-desmethyl-sildenafil) was not tested. Sildenafil is metabolized to its active metabolite ( $\mathrm{N}$-desmethyl sildenafil), which accounts for about one-fifth of the drug's activity [23]. Third, this study was conducted only with healthy intact male beagle dogs. Additional pharmacokinetic studies on canine patients with $\mathrm{PH}$ are needed. Fourthly, accurate bioavailability measurements using intravenous sildenafil were not conducted since intravenous sildenafil was not available.

\section{Conclusions}

The pharmacokinetic profiles of oral administration were not significantly different between sildenafil FCT and ODF. Bioavailability with rectal administration was lower compared with oral administration of the same dose. All the dogs tolerated the experiment well without serious AEs. These results suggest that sildenafil ODF formulation can be used interchangeably with the FCT formulation and that rectal administration of ODF could be beneficial to canine $\mathrm{PH}$ patients. Additional studies would be needed to determine the appropriate rectal dose of sildenafil to achieve therapeutic levels similar to those obtained with oral administration.

\section{Methods \\ Animals}

Twelve intact male beagle dogs from a research colony at the College of Veterinary Medicine of Chungnam National University were included in the study. The animals were fed commercial dry food and had free access to water. The dogs were 4-7 years of age and weighed 9-13 kg. They each had normal physical and neurologic examinations; the complete blood counts and serum chemistry panels revealed no abnormalities, and the systemic systolic blood pressure, measured by Doppler method, was within normal range. This study obtained the approval of Institutional Animal Care and Use Committee (IACUC) at Chungnam National University (approval number, CNU-00749). After the study, 2 dogs were adopted as pets and the rest are waiting for adoption.

\section{Experimental design and sample collection}

This was a randomized, open-label, single-dose, 4-way crossover study performed to evaluate sildenafil FCT and ODF with a washout period of 1 week. Before the administration of sildenafil, foods were withheld for over $20 \mathrm{~h}$. Each dog received four separate doses of sildenafil in the following forms, dosages, and routes: (1) FCT formulation of sildenafil $2 \mathrm{mg} / \mathrm{kg}$ orally (FCT $2 \mathrm{mg} / \mathrm{kg} \mathrm{PO}$ ), (2) ODF formulation of sildenafil $2 \mathrm{mg} / \mathrm{kg}$ orally (ODF $2 \mathrm{mg} /$ $\mathrm{kg}$ PO), (3) ODF formulation of sildenafil $2 \mathrm{mg} / \mathrm{kg}$ dissolved in distilled water $(2 \mathrm{mg} / \mathrm{ml}$ ) rectally (Rectal $2 \mathrm{mg} / \mathrm{kg}$ ), and (4) ODF formulation of sildenafil $10 \mathrm{mg} / \mathrm{kg}$ dissolved in distilled water $(3.3 \mathrm{mg} / \mathrm{ml})$ rectally (Rectal $10 \mathrm{mg} / \mathrm{kg}$ ).

FCT formulation of sildenafil $\left(\right.$ Viagra $\left.^{\circ}\right)$ and ODF formulation of sildenafil (Viagra- $\mathrm{L}^{\circ}$ ) were purchased from Pfizer Korea Pharm. Co. (Seoul, South Korea). For FCT oral administration, sildenafil citrate was prepared in capsule form. For ODF oral administration, ODF formulation of sildenafil was cut according to the body weight of each subject. In preparation for rectal administration, 
ODF formulation of sildenafil was diluted in distilled water just before administration [13]. Given that the solubility of ODF is $3.5 \mathrm{mg} / \mathrm{ml}$, the solution was diluted to a concentration lower than that. After administering an enema, this solution was administered rectally using a $10 \mathrm{~mL}$ or $30 \mathrm{~mL}$ syringe with a 9-cm flexible zonde [14]. The zonde was flushed with $1 \mathrm{~mL}$ of additional distilled water, and the anus was closed manually for $5 \mathrm{~min}$ to prevent early expulsion of the drug. Baseline blood collection was performed just before each administration. Eleven additional blood samples were collected at $10,20,40,60,120,240,360,480,600,720$, and $1440 \mathrm{~min}$, respectively, after administration. All blood samples were collected from the jugular vein with a $23 \mathrm{~g}$, $5 \mathrm{~mL}$ syringe. All of these were immediately drawn into heparinized tubes, and then the plasma was separated within 30 min and immediately frozen at $-80{ }^{\circ} \mathrm{C}$. A small meal was provided to the dog after blood collection, which was performed $4 \mathrm{~h}$ after sildenafil administration.

Throughout the study, the dogs were observed for AEs for $24 \mathrm{~h}$ after each drug administration. In order to evaluate $\mathrm{AE}$, we continuously monitored the clinical symptoms and performed physical examinations. Systemic systolic blood pressure was monitored by Doppler method. Four doses had been missed due to animal hyperactivity and technical error (one in ODF orally, one in $2 \mathrm{mg} / \mathrm{kg}$ rectally, two in $10 \mathrm{mg} / \mathrm{kg}$ rectally). Data from those four missed doses were excluded.

\section{Measurement of plasma sildenafil concentration}

The plasma concentration of sildenafil was determined by liquid chromatography-tandem mass spectrometry. For the high-performance liquid chromatography (HPLC) separation and the tandem mass spectrometry detection, plasma samples were pretreated using the following method. An aliquot $(50 \mu \mathrm{L})$ of internal standard solution (carbamazepine $10 \mathrm{ng} / \mathrm{mL}$ in acetonitrile) was added to an aliquot $(50 \mu \mathrm{L})$ of plasma. Thereafter, $400 \mu \mathrm{L}$ of acetonitrile was added to the samples to induce the precipitation of plasma proteins. The resulting mixture was mixed vigorously for $10 \mathrm{~min}$ and centrifuged at $13,500 \mathrm{rpm}$ for $10 \mathrm{~min}$. An aliquot $(5 \mu \mathrm{L})$ of supernatant was directly injected into the LC-MS/MS system.

The separation by chromatography was performed with reverse phase column (Agilent ZORBAX C18, $3 \mu \mathrm{m}, 2.1 \times 50 \mathrm{~mm}$ ) equipped with guard column (Agilent ZORBAX C8, $5 \mu \mathrm{m}, 2.1 \times 12.5 \mathrm{~mm}$ ) and Agilent HPLC system (Agilent Technologies, Santa Clara, CA, USA). Detection was conducted by triple quadrupole tandem mass spectrometer system (API 4000, Applied Biosystems/MDS SCIEX, Foster City, CA, USA). The molecular ion fragmentation of sildenafil and carbamazepine was performed under the condition of collision energy at $53 \mathrm{~V}$ and $29 \mathrm{~V}$, respectively, by collision-activated dissociation with nitrogen as the collision gas. A multiple reaction monitoring mode was used for quantification at $\mathrm{m} / \mathrm{z} 475.2$ to 283.2 for sildenafil and $\mathrm{m} / \mathrm{z} 237.2$ to 194.2 for carbamazepine. The peak area for all components were automatically integrated using Analyst software version 1.5.1 (Applied Biosystems/MDS SCIEX). The quantifiable range of the plasma samples was 0.001 to $10 \mu \mathrm{g} / \mathrm{mL}$. The retention times of sildenafil and carbamazepine were $4.11 \mathrm{~min}$ and $4.26 \mathrm{~min}$, respectively.

\section{Analysis of the data}

To estimate the pharmacokinetic parameters of sildenafil, the plasma concentration for each beagle dog was analyzed by non-compartmental model analysis with non-linear regression using WinNonlin 4.1 software package (Pharsight, Cary, NC). The elimination rate constant (ke) was determined by linear regression of the log-linear portion of the terminal phase. The terminal elimination half-life $\left(\mathrm{T}_{1 / 2}\right)$ was calculated by dividing the natural logarithm of 2 (0.693) under each ke value. The area under the sildenafil concentration-versus-time curve, from time zero to the time of the last quantifiable concentration $\left(\mathrm{AUC}_{\text {last }}\right)$, was calculated using the linear trapezoidal rule and the standard area extrapolation method from WinNonlin 4.1. The $\mathrm{C}_{\max }$ and $\mathrm{T}_{\max }$ were directly compiled from the concentration-time curves. One-way ANOVA was used to evaluate differences in the pharmacokinetic parameters among treatment arms. If there were any differences, Duncan's test was used to determine if these differences were significant or not.

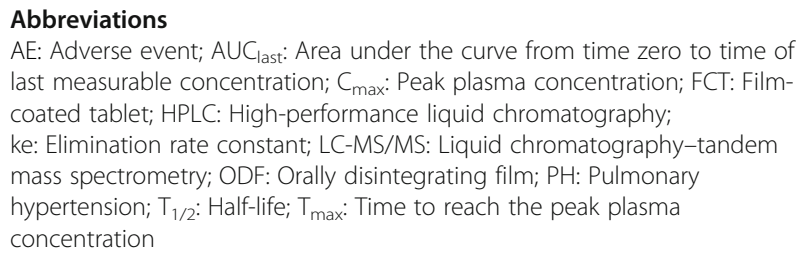

\section{Acknowledgements}

This manuscript is written based on the Master's thesis of author Hyuck-Joo Yang.

\section{Funding}

This research was supported by the Bio \& Medical Technology Development Program of the National Research Foundation (NRF) and funded by the Korean government (MSIT) (No. 2017M3A9C8021844).

\section{Availability of data and materials}

Raw data for tables and figures of the current study are available from the corresponding author on reasonable request.

\section{Authors' contributions}

HJY performed the clinical procedures and drafted the manuscript. YIO performed data analysis and interpretation and critically revised the manuscript. JWJ performed pharmacokinetic analysis and contributed to statistical analysis. KHS contributed to statistical and scientific discussions. TSK participated in the study design and revised the manuscript. KWS provided the concept design and academic direction and contributed to editing and drafting of the manuscript. All authors have read and approved the final manuscript. 


\section{Competing interest}

The authors declare that they have no competing interests.

\section{Ethics approval and consent to participate}

All animal procedures undertaken were approved by Institutional Animal Care and Use Committee (IACUC) at Chungnam National University (approval number, CNU-00749).

\section{Consent for publication}

Not applicable.

\section{Publisher's Note}

Springer Nature remains neutral with regard to jurisdictional claims in published maps and institutional affiliations.

\section{Author details}

'Department of Veterinary Internal Medicine, College of Veterinary Medicine, Chungnam National University, Daejeon 34134, Republic of Korea.

${ }^{2}$ Department of Veterinary Internal Medicine, College of Veterinary Medicine, Seoul National University, Seoul 08826, Republic of Korea. ${ }^{3}$ Graduate School of New Drug Discovery and Development, Chungnam National University, Daejeon 34134, Republic of Korea.

Received: 6 May 2018 Accepted: 16 September 2018

Published online: 24 September 2018

\section{References}

1. Kellihan HB, Stepien RL. Pulmonary hypertension in dogs: diagnosis and therapy. Vet Clin North Am Small Anim Pract. 2010;40:623-41.

2. Simonneau G, Galie N, Rubin LJ, Langleben D, Seeger W, Domenighetti G, Gibbs S, Lebrec D, Speich R, Beghetti M. Clinical classification of pulmonary hypertension. J Am Coll Cardiol. 2004;43:S5-S12.

3. Johnson L, Boon J, Orton EC. Clinical characteristics of 53 dogs with Doppler-derived evidence of pulmonary hypertension: 1992-1996. J Vet Intern Med. 1999;13:440-7.

4. Bach JF, Rozanski EA, MacGregor J, Betkowski JM, Rush JE. Retrospective evaluation of sildenafil citrate as a therapy for pulmonary hypertension in dogs. J Vet Intern Med. 2006;20:1132-5.

5. Brown A, Davison E, Sleeper M. Clinical efficacy of sildenafil in treatment of pulmonary arterial hypertension in dogs. J Vet Intern Med. 2010;24:850-4.

6. Kellum HB, Stepien RL. Sildenafil citrate therapy in 22 dogs with pulmonary hypertension. J Vet Intern Med. 2007;21:1258-64.

7. Toyoshima Y, Kanemoto I, Arai S, Toyoshima H. A case of long-term sildenafil therapy in a young dog with pulmonary hypertension. J Vet Med Sci. 2007;69:1073-5.

8. Galiè N, Ghofrani HA, Torbicki A, Barst RJ, Rubin LJ, Badesch D, Fleming T, Parpia T, Burgess G, Branzi A. Sildenafil citrate therapy for pulmonary arterial hypertension. N Engl J Med. 2005;353:2148-57.

9. Roh H, Son H, Lee D, Yeon KJ, Kim HS, Kim H, Park K. Pharmacokinetic comparison of an orally disintegrating film formulation with a film-coated tablet formulation of sildenafil in healthy Korean subjects: a randomized, open-label, single-dose, 2-period crossover study. Clin Ther. 2013;35:205-14.

10. Lepore JJ, Maroo A, Bigatello LM, Dec GW, Zapol WM, Bloch KD, Semigran MJ. Hemodynamic effects of sildenafil in patients with congestive heart failure and pulmonary hypertension: combined administration with inhaled nitric oxide. Chest. 2005;127:1647-53.

11. Michelakis E, Tymchak W, Lien D, Webster L, Hashimoto K, Archer S. Oral sildenafil is an effective and specific pulmonary vasodilator in patients with pulmonary arterial hypertension: comparison with inhaled nitric oxide. Circulation. 2002;105:2398-403.

12. Radicioni M, Castiglioni C, Giori A, Cupone I, Frangione V, Rovati S. Bioequivalence study of a new sildenafil $100 \mathrm{mg}$ orodispersible film compared to the conventional film-coated $100 \mathrm{mg}$ tablet administered to healthy male volunteers. Drug Des Devel Ther. 2017;11:1183.

13. Brewer D, Cerda-Gonzalez S, Dewey C, Boothe D, Van Horne K. Pharmacokinetics of single-dose rectal zonisamide administration in normal dogs. J Vet Intern Med. 2015;29:603-6.

14. Peters $R$, Schubert T, Clemmons R, Vickroy T. Levetiracetam rectal administration in healthy dogs. J Vet Intern Med. 2014;28:504-9.

15. Giorgi M, Łebkowska-Wieruszewska B, Lisowski A, Owen H, Poapolathep A, Kim T, De Vito V. Pharmacokinetic profiles of the active metamizole metabolites after four different routes of administration in healthy dogs. J Vet Pharmacol Ther. 2018:41:428-36.

16. De Vito V, Łebkowska-Wieruszewska B, Shaban A, Lisowski A, Kowaski CJ, Giorgi M. Pharmacokinetic profiles of the analgesic flupirtine in dogs after the administration of four pharmaceutical formulations. Vet Anaesth Analg. 2015;42:629-37.

17. Michael SL. Colonoscopy. In: Tams TR, Rawlings CA, editors. Small animal endoscopy. 3rd ed. St. Louis: Elsevier; 2010. p. 217-44.

18. Schwartz M, Muñana K, Nettifee-Osborne J, Messenger K, Papich M. The pharmacokinetics of midazolam after intravenous, intramuscular, and rectal administration in healthy dogs. J Vet Pharmacol Ther. 2013;36:471-7.

19. Gerecke M. Chemical structure and properties of midazolam compared with other benzodiazepines. Br J Clin Pharmacol. 1983;16(Suppl 1):11-6.

20. Zhang J, Niu S, Zhang H, Streisand JB. Oral mucosal absorption of midazolam in dogs is strongly pH dependent. J Pharm Sci. 2002;91:980-2.

21. Code of Federal Regulations Title 21, Volume 6. U.S. Food and Drug Administration, Silver Spring. 2018. https://www.ecfr.gov/cgi-bin/textidx?SID=f36252f506c2dd199ddee096d9aeaf45\&mc=true\&node=se21.6.514_ $13 \&$ rgn=div8. Accessed 14 June 2018.

22. Barletta M, Scansen BA. Sildenafil citrate. In: Plumb DC, editor. Plumb's veterinary drug handbook. 9th ed. Hoboken: Wiley-Blackwell; 2018. p. 1485-7.

23. Simiele M, Pensi D, Pasero D, Ivaldi F, Rinaldi M, Di Perri G, Ranieri VM, D'Avolio A. Development and validation of an ultra performance liquid chromatography tandem mass method for sildenafil and N-desmethyl sildenafil plasma determination and quantification. J Chromatogr B Analyt Technol Biomed Life Sci. 2015;1001:35-40.
Ready to submit your research? Choose BMC and benefit from:

- fast, convenient online submission

- thorough peer review by experienced researchers in your field

- rapid publication on acceptance

- support for research data, including large and complex data types

- gold Open Access which fosters wider collaboration and increased citations

- maximum visibility for your research: over $100 \mathrm{M}$ website views per year

At BMC, research is always in progress.

Learn more biomedcentral.com/submissions 